\title{
Ventricular septal defect in a world class runner
}

\author{
A Boraita, J Esteve-Lanao, M Pérez, M Rabadán, C Foster, A Lucia
}

Br J Sports Med 2005;39:e32 (http://www.bjsportmed.com/cgi/content/full/39/7/e32). doi: 10.1136/bjsm.2004.016071

\begin{abstract}
We report the case of an elite male, East African endurance runner ( 18 years old) who ranked in the top 15 in the World Cross Country Championships (sub 21 year old category) despite having a ventricular septal defect (VSD; width: $0.22 \mathrm{~cm}$ ) that was diagnosed 2 weeks after this event with echocardiographic evaluation. This athlete was a moderate altitude native $(\sim 3000 \mathrm{~m})$. Cardiac dimensions were within normal limits and no significant pathological signs were observed. His $\mathrm{Vo}_{2 \max }$ was relatively low given his performance level $\left(67.9 \mathrm{ml} \mathrm{kg}^{-1} \mathrm{~min}^{-1}\right)$. Despite his limited training background (only 1 year), his running economy was, however, better than the values reported in our laboratory for Caucasian runners of the same age. Further cardiological follow up might confirm that the VSD causes no pathological effects or any performance detriment in future years.
\end{abstract}

$\mathrm{V}$ ntricular septal defects (VSD) are one of the most common cardiac abnormalities encountered in a paediatric population. ${ }^{1}$ This type of lesion is very rare in the developed world because: (i) the prominent murmur associated with most defects makes it easy to detect during infancy or childhood, which leads to surgical repair before the patient reaches adulthood; and (ii) small VSD undergo spontaneous closure before adulthood. ${ }^{2}$ Patients operated on for VSD in childhood are usually considered to be cured. However, anatomical, haemodynamic, functional, electrical, and echocardiographic abnormalities may persist, justifying long term cardiological follow up. ${ }^{1}$

No reports are available on the occurrence of VSD in elite athletes. Besides its potential pathological effects, a VSD might have a deleterious effect on sports performance making achievement of elite status unlikely. From 1989 to April 2003, 5285 elite (Olympic class) athletes of both sexes (mostly Caucasians, with mean ages of 23 years (male) and 21 years (female)) from more than 30 sports disciplines (endurance sports, track and field, team sports, etc) underwent one or more echocardiographic evaluations (a mean of six evaluations per athlete) in our sports cardiology department. In this large series of evaluations, however, we only identified one case of VSD, diagnosed in April 2003, which is described below. This very low incidence in elite athletes would suggest, at least partly, that VSD are normally self limiting conditions that preclude participation in competitive sports.

\section{CASE REPORT}

We report the case of an elite male, East African endurance runner ( 18 years old) who ranked in the top 15 in the World Cross Country Championships (sub 21 year old category) despite having a VSD that was diagnosed 2 weeks after this event, as explained below. Written informed consent was obtained from the subject in accordance with the local ethics committee.

The subject was born and raised (and has always lived and trained) in Asmara (Eritrea), at an altitude of $\sim 3000 \mathrm{~m}$.
Despite his top level performance, he had only been training seriously for about 1 year.

No cardiac risk factor was identified in his history. Cardiac auscultation evidenced a grade II/IV systolic murmur at both the cardiac apex and left sternal border. No other abnormalities were found and resting blood pressure was low at 100/ $60 \mathrm{~mm} \mathrm{Hg}$. Electrocardiographic (ECG) recording was compatible with the typical ECG tracing expected of the so called "athlete's heart", that is, signs of early repolarisation or high $\mathrm{T}$ wave voltages and left ventricular (LV) hypertrophy.

Transthoracic M-mode, two-dimensional, colour Doppler echocardiographic evaluation was performed by an experienced cardiologist, who had performed one or more echocardiographic evaluations in each of $\sim 5000$ elite athletes. A perimembranous VSD (width: $0.22 \mathrm{~cm}$; length: $0.80 \mathrm{~cm}$ ) was detected in the long parasternal axis and colour imaging revealed the occurrence of a turbulent systolic, left to right shunt through the lesion with a speed of $4.12 \mathrm{~m} \mathrm{~s}^{-1}$ (fig 1). Pulmonary and systemic minute volume were 6.24 and $6.25 \mathrm{l} \mathrm{min}^{-1}$, respectively. No valve abnormalities or echocardiographic signs of pulmonary hypertension were detected, although the inter-ventricular pressure gradient was $68 \mathrm{~mm} \mathrm{Hg}$ and the systolic pressure of the right ventricle (RV) was close to the upper physiological limit of $35 \mathrm{~mm} \mathrm{Hg}$, that is, $32 \mathrm{~mm} \mathrm{Hg}$ with a RV/LV pressure ratio of $32 \%$. Ejection fraction was $63 \%$ and main cardiac dimensions were within normal limits and compatible with the values usually found in our centre in young elite endurance athletes: interventricular septal wall thickness at end-diastole (IVSTd): $8 \mathrm{~mm}$; left ventricular end-diastolic internal diameter (LVIDd): $54 \mathrm{~mm}$; right ventricular outflow tract: $29 \mathrm{~mm}$; aortic root dimension: $34 \mathrm{~mm}$; antero-posterior left atrial dimension (LAD): $31 \mathrm{~mm}$; and longitudinal right (LRAD) and left atrial dimensions (LLAD) of 49 and $48 \mathrm{~mm}$, respectively. Estimated left ventricular mass index corrected by body surface area (LVMI, in $\left.\mathrm{g} \mathrm{m}^{-2}\right)^{4}$ was $80 \mathrm{~g} \mathrm{~m}^{-2}$.

The $\mathrm{Vo}_{2 \max }$ of the subject (measured in our laboratory at $\sim 600 \mathrm{~m}$ altitude) was $67.9 \mathrm{ml} \mathrm{kg}{ }^{-1} \mathrm{~min}^{-1}$, that is, below those levels reported in the best East African runners at sea level (mean of $\sim 80 \mathrm{ml} \mathrm{kg}^{-1} \mathrm{~min}^{-1}$ ) ${ }^{5}$ and also below the values of Caucasian (Spanish) elite runners of his same age tested in our laboratory (mean of $72.1 \mathrm{ml} \mathrm{kg}^{-1} \mathrm{~min}^{-1}$ ). Nevertheless, the relatively low $\mathrm{Vo}_{2 \max }$ of the subject was compensated for by a better running economy ( $\mathrm{Vo}_{2}$ of 46.9 , 52.3, and $54.6 \mathrm{ml} \mathrm{kg}^{-1} \mathrm{~min}^{-1}$ at 17,19 , and $21 \mathrm{~km} \mathrm{~h}^{-1}$, respectively) than the values usually recorded in our laboratory in Caucasian runners during gradual treadmill protocols at $1 \%$ upgrade $\left(\mathrm{Vo}_{2}\right.$ of 50.7, 55.7, and $61.8 \mathrm{ml} \mathrm{kg}^{-1} \mathrm{~min}^{-1}$ at 17,19 , and $21 \mathrm{~km} \mathrm{~h}^{-1}$, respectively), evidencing a good adaptation to endurance running.

Abbreviations: ECG, electrocardiographic; IVSTd, interventricular septal wall thickness at end-diastole; LAD, left atrial dimension; LLAD, longitudinal left atrial dimension; LRAD, longitudinal right atrial dimension; LV, left ventricle; LVMI, left ventricular mass index; RV, right ventricle; VSD, ventricular septal defect 


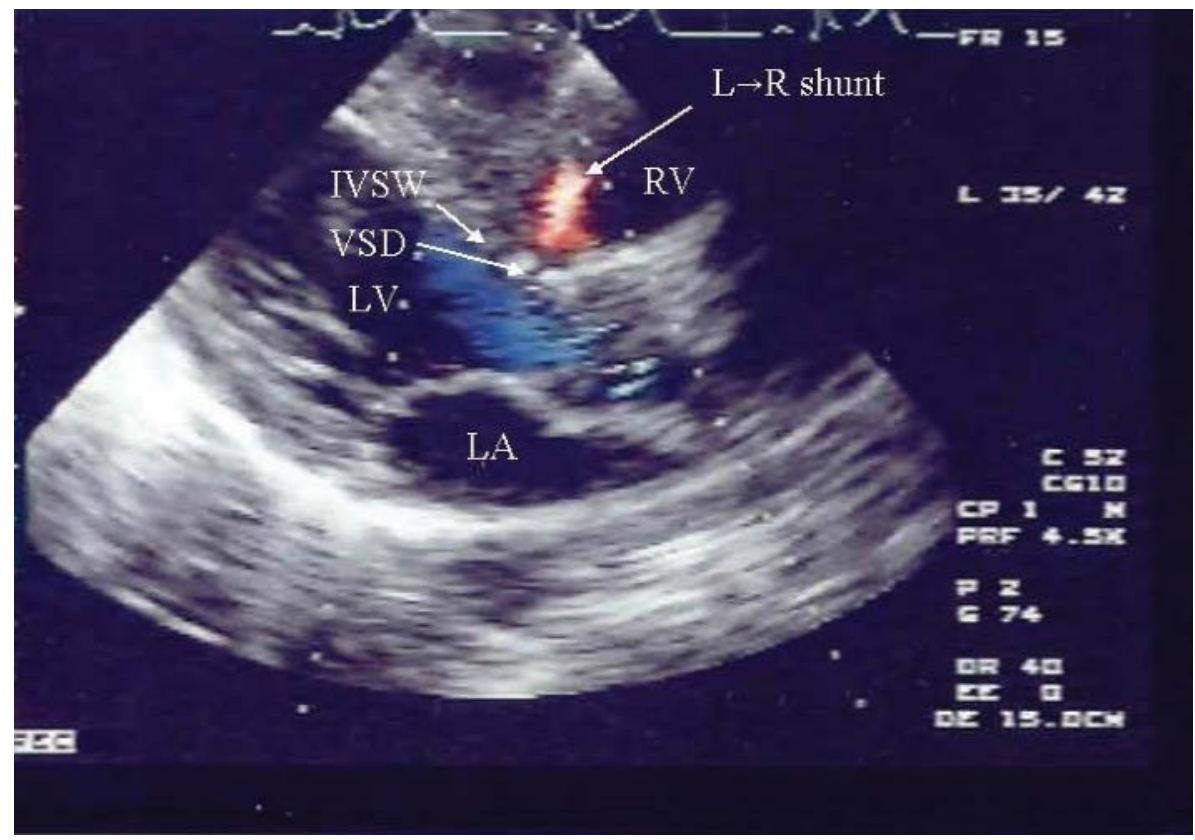

Figure $1 \mathrm{M}$-mode, two-dimensional, colour Doppler echocardiographic evaluation. A perimembranous ventricular septal defect (width: $0.22 \mathrm{~cm}$; length: $0.80 \mathrm{~cm}$ ) was detected in the long parasternal axis as there was lack of continuity in the perimembranous portion of the interventricular septal wall. LA, left atria; $L \rightarrow R$ shunt, left to right shunt; IVSW, interventricular septal wall; LV, left ventricle; RV, right ventricle; VSD, ventricular septal defect.

We found no medical contraindication for the athlete continuing his sporting career. Nonetheless, given the lack of published data on this abnormality in elite sportsmen, a potential limitation on maximal pump capacity cannot be totally ignored in an elite, world class endurance runner. He was advised to undergo an echocardiographic evaluation on a yearly basis. Since it would be very difficult for the subject to access this type of medical follow up in his country of origin, due to lack of economic resources and sports cardiology/ medicine centres, he was invited to be evaluated in our centre during his future visits to our country and to stay in contact with us or with other cardiologists.

\section{Authors' affiliations}

A Boraita, M Rabadán, Department of Cardiology, Sport Medicine Center, Higher Sports Council, Madrid, Spain

J Esteve-Lanao, M Pérez, A Lucia, Exercise Physiology Laboratory, European University of Madrid, Madrid, Spain

C Foster, Department of Exercise and Sport Science, University of Wisconsin-La Crosse, La Crosse, WI, USA

This study was part of a project supported by the Consejo Superior de Deportes (02/UPR 10/04).

Competing interests: none declared

This subject detailed in this case report gave consent for his details to be published.

This subject was evaluated, together with other African runners, in a study that was approved by the local ethics committee (Universidad Europea, Madrid, SPAIN).

Correspondence to: Alejandro Lucia, Universidad Europea de Madrid, Departamento de Ciencias Morfologicas y Fisiology, Edificio A, Despacho 330, E-18670 Madrid, Spain; alejandro.lucia@uem.es

\section{What is already known in the topic}

No report is available on the occurrence of ventricular septal defects in elite athletes. Furthermore, this type of lesion is very rare in adults (non-athletes) of western countries.

\section{What this study adds}

A ventricular septal defect is reported for the first time in a top level, East African runner. Although this lesion does not seem to have impaired his athletic performance so far, further cardiac follow up is necessary in the future.

Accepted 29 November 2004

\section{REFERENCES}

1 Chantepie A. Ventricular septal defects in the adult. Arch Mal Coeur Vaiss 2002;95:1074-80.

2 Soto B, Becker AE. Classification of ventricular septal defects. Br Heart J 1980;43:332-43.

3 Boraita Pérez A, Serratosa F. "The athlete's heart": most common electrocardiographic findings. Rev Esp Cardiol 1998;51:356-68.

4 Devereux RB, Alonso DR, Lutas EM, et al. Echocardiographic assessment of left ventricular hypertrophy. Comparison to necropsy findings. Am J Cardiol 1986;57:450-8.

5 Saltin B, Larsen H, Terrados N, et al. Aerobic exercise capacity at sea level and at altitude in Kenyan boys, junior and senior runners compared with Scandinavian runners. Scand J Med Sci Sports 1995;5:209-21. 